\title{
EL ARTE DE LA LÍRICA EN LA CLASE DE LITERATURA: ALGUNAS CONSIDERACIONES PARA POSIBLES ABORDAJES AL POEMA BASADOS EN LA OBRA DE HELENA KOLODY
}

\author{
THE LIRIC ART IN THE LITERATURE CLASS: \\ ALGUNAS CONSIDERACIONES PARA POSIBLES ABORDAJES AL POEMA \\ BASADOS EN LA OBRA DE HELENA KOLODY
}

\author{
Cristian Javier López ${ }^{1}$ \\ Vilson Pruzak dos Santos ${ }^{2}$
}

\begin{abstract}
Resumen: La clase de literatura es un espacio propicio para la formación integral del sujeto mediante la reflexión sobre la relación autor, obra y sociedad. Para ello, la tarea del docente se encaminará a elegir cuál será la perspectiva utilizada para el trabajo con el texto literario y la importancia de éste para el alumnado. El presente trabajo reflexiona sobre la importancia del abordaje al texto literario de manera crítica y pretende contribuir con un posible abordaje al estudio de la poesía en clase. Para ello será utilizado como ejemplo una obra de la escritora paranaense Helena Kolody bajo la temática de la crítica social.
\end{abstract}

Palabras clave: Helena Kolody; Literatura latinoamericana; Escritura femenina.

Resumo: A aula de literatura apresenta-se como um espaço propício para a formação integral do sujeito mediante a reflexão sobre a relação autor, obra e sociedade. Para isso, a tarefa do docente encaminhar-se-á a selecionar qual será a perspectiva utilizada para o trabalho com o texto literário e a importância deste para o alunado. $\mathrm{O}$ presente trabalho reflete sobre a importância da abordagem ao texto literário de maneira crítica e pretende contribuir com uma possível abordagem ao estudo da poesia na sala de aula. Para isso será utilizado como exemplo uma obra da escritora paranaense Helena Kolody sob a temática da crítica social.

Palavras-chave: Helena Koldy; Literatura latino-americana; Escrita feminina.

\footnotetext{
${ }^{1}$ Doctorando del Programa de Pos grado Interuniversitario en Estudios Literarios de la Universidade de Vigo, UVIGO, España. Máster en Teatro y Artes Escénicas, área de estudios literarios, por la Universidade de Vigo. Licenciado en Letras Portugués/Español por la Universidade Estadual do Oeste do Paraná-Unioeste/CascavelPR, Brasil. Licenciado en Música y Licenciado en Artes Visuales por la Faculdade Anhanguera/Cascavel-PR, Brasil. Integrante do Grupo de Investigación "Ressignificações do passado na América; processos de leitura, escrita e tradução de gêneros híbridos de história e ficção - vias para a descolonização". E-mail: cj_lopez2@hotmail.com

${ }^{2}$ Mestrando do Programa de Mestrado Profissional em Letras - Profletras - da UnioestelCascavel-PRIUFRNRN. Graduado em Letras - Português\Inglês pela Universidade Paranaense- UNIPAR. Professor de Língua Portuguesa do "Colégio Estadual do Campo de Rio do Salto" e do "Centro de Educação de Jovens e Adultos Professora Joaquina de Mattos Branco". Integrante do Grupo de Investigación "Ressignificações do passado na América; processos de leitura, escrita e tradução de gêneros híbridos de história e ficção - vias para a descolonização". E-mail: vilson19842009@ hotmail.com
} 


\section{Introducción}

La literatura nos permite como docentes el abordaje al texto desde diferentes perspectivas que colaboran con el proceso de enseñanza y aprendizaje y así, también, pueden contribuir con la formación integral del sujeto social. Tales perspectivas nos permiten trabajar con el texto, por ejemplo, desde su estructura, el mensaje propuesto por el autor, los diálogos establecidos entre éste con otras ramas del saber, etc. En este sentido, el área de la lírica se presenta, sin desmerecer las contribuciones de los géneros narrativo y dramático, como un género capaz de mostrar el dominio de los signos lingüísticos en un alto nivel de complejidad y que, lejos de ser un arte inaccesible o poco comprensible, puede convertirse en un gran aliado al momento de exponer la relación entre la obra literaria y la expresión de los sujetos en confluencia con la sociedad.

Consideramos que el dominio lingüístico al cual nos referimos se fundamenta en que el mencionado género literario se construye básicamente por medio de la condensación de ideas en un texto que, por lo general, posee una corta extensión y que prioriza el uso metafórico del lenguaje. Esto nos lleva a pensar en la manipulación del lenguaje necesaria que el escritor ejerce sobre la lengua cuando desea transmitir sus ideas, crear imágenes o exponer algún concepto y todo ello de forma artística. Vemos así, que el poema, en su acotado cuerpo textual, presenta un uso sofisticado de la lengua que explota las capacidades comunicativas de la misma al máximo. Este hecho en la clase de literatura nos permite, además, que reflexionemos junto con el alumnado acerca del poder de la palabra y la importancia del dominio de la misma. En este sentido, es importante destacar también el papel relevante que tales reflexiones poseen en el espacio del continente americano que históricamente se construyó como un espacio híbrido en el que el enfrentamiento y la dominación se dio de manera hostil, también, por medio de la lengua.

Dentro del espacio de la clase de literatura, y especialmente cuando nos valemos de la lírica, la idea de manipulación de la lengua se fundamenta en los tres niveles básicos que el poema nos proporciona: el formal, el fónico/sonoro y el conceptual. Estamos trabajando, por lo tanto, con una producción que posibilita la expresión de sentimientos, imágenes e ideas aunados a la sonoridad de la lengua mediante una forma o estructuración específica para la transmisión de un mensaje. La lengua, en este caso, es utilizada y abordada desde la perspectiva artística, hecho que coloca al discurso del escritor en un lugar diferente a aquel que podría ser utilizado para la expresión o defensa de una idea en otro género textual. En este 
sentido, el docente, al valerse de obras literarias para la enseñanza busca desarrollar la integridad de las potencias de su alumnado pues

[...] o texto literário tem muito a contribuir para o aprimoramento pessoal, para o autoconhecimento, sem falar do constante desvelamento do mundo e da grande possibilidade que a leitura de determinada obra oferece para o descortínio de novos horizontes para o homem, no sentido da formação e do refinamento da personalidade. (SILVEIRA, 2005, p. 16).

De este modo, mediante el arte podemos incentivar a una conciencia crítica que reflexione sobre la realidad a partir de diferentes perspectivas. En este sentido no se trata de condicionar el pensamiento de los sujetos, sino de expandir el horizonte de ideas de los mismos y enseñar otras posibles visiones por medio de la obra literaria. Aquí se revela la importancia de lo que expresa Soares (2004, p. 6), al mencionar que en países que se quieren desarrollados "as práticas sociais de leitura e de escrita assumem a natureza de problemática relevante" (SOARES, 2004, p. 6), e así debe de ser para los docentes que buscan formar ciudadanos conscientes.

Por otro lado, siguiendo la noción del texto lírico como objeto artístico, los docentes debemos pensar que cuando exponemos el poema al alumnado estamos trabajando con un objeto sonoro, conforme expone la poeta y crítica literaria uruguaya Idea Vilariño (2016), y, por lo tanto, su conexión con la musicalidad de la lengua es un aspecto importante de este género que debe ser considerado al momento de desarrollar su lectura. La presentación de una obra lírica no debe limitarse a la palabra escrita sino que requiere la existencia de una sensibilidad que dirija el trabajo, primeramente, desde la declamación, con una lectura fluida y cuidando la dicción, hasta el análisis y conocimiento de la obra en profundidad.

Para este artículo buscamos exponer un breve análisis basado en un poema de la autora paranaense Helena Kolody (1912-2004), bajo la temática de la crítica social y las consecuencias que trae la guerra. La mencionada poeta, que goza de prestigio en el Estado de Paraná, sur de Brasil, es una de las voces femeninas del sur del continente que explora en su obra, además de su desencanto con las injusticias sociales y las catástrofes advenidas de la guerra, temas como el paso del tiempo, la figura del inmigrante y la musicalidad.

No obstante, con este trabajo, procuramos destacar la temática de la crítica social para el conocimiento de expresiones que reflexionan acerca de los acontecimientos sociales desde la mirada femenina en la literatura escrita por mujeres que históricamente fue silenciada en el continente. Entendemos, con esto, la importancia que conlleva el contribuir también con los 
estudios que desean hacer visibles las obras de autoras del continente que, en comparación con las producciones masculinas, se encuentran en condición de inferioridad cuantitativamente.

Esperamos con este trabajo aportar a los profesionales de la educación algunas visiones sobre la importancia del arte lírico en la clase de literatura y los posibles abordajes del poema como contribución para este arte y también como el rescate de la palabra femenina crítica en el continente americano.

\section{Las obras producidas en el continente americano: algunas consideraciones para la clase de literatura}

El proceso de enseñanza y aprendizaje de literatura supone la elección del lugar de enunciación desde el cual el docente estará exponiendo el contenido. Por lo tanto, consideramos que al tratar acerca de las literaturas producidas en el continente americano este proceso debe ser pensado cuidando las particularidades que el espacio latinoamericano exige. Las literaturas producidas en este espacio se originan de las lenguas impuestas a partir del proceso de colonización. Este hecho un tanto obvio, aunque de modo alguno simple, debe llamarnos la atención a los docentes de literatura, pues estamos trabajando con un producto que deriva, por un lado, de una estructura lingüística con una carga histórica e ideológica anterior a su llegada al continente y, por otro lado, mediante el proceso cultural de hibridación con las nuevas sociedades en América, las nuevas formas y nuevas expresiones que la lengua ganó a partir de esta confluencia.

Es decir, las literaturas del continente americano poseen una doble visión desde su génesis que como docentes debemos tener presente para no ser simples reproductores que cumplan con la transmisión ciega del contenido exigido por el sistema educativo. Para entender esta postura, mencionamos las consideraciones efectuadas por el mexicano Octavio Paz, quien expone que las literaturas producidas en el continente

[...] son literaturas escritas en lenguas transplantadas. Las lenguas nacen y crecen en un suelo; las alimenta una historia común. Arrancadas de su suelo natal y de su tradición propia, plantadas en un mundo desconocido [...] se transformaron. Son la misma planta y una planta distinta. Nuestras literaturas no vivieron pasivamente las vicisitudes de las lenguas transplantadas [...] dejaron de ser meros reflejos transatlánticos; a veces han sido la negación de las literaturas europeas y otras, con más frecuencia, su réplica. (PAZ, 1991, p. 8). 
En este sentido, el de las lenguas transplantadas de Europa para América, tenemos que replantearnos cuál será la perspectiva utilizada cuando impartimos la clase de literatura y bajo qué concepción seleccionaremos los textos que serán expuestos al alumnado. Este punto es crucial pues nos ayuda a comprender, por ejemplo, la importancia de las variantes de la lengua utilizadas por los autores latinoamericanos, el proceso cultural de hibridación en el continente que se refleja en las producciones literarias, las temáticas explotadas en el quehacer poético, la relación de la obra con su contexto socio-cultural, etc.

Para ilustrar este hecho, y entender de modo práctico las consideraciones de Octavio Paz, podemos pensar en las literaturas escritas en la variante culta de la lengua portuguesa brasileña, que presenta notorias diferencias con la variante portuguesa europea, o la exploración de temáticas referentes a problemas sociales que mediante el poema pretenden despertar la complicidad del público en la lectura de las obras y que sólo obtienen importancia con el grado de significación que se efectúe entre ellos.

Así, la tarea del docente en el ámbito literario no debe fijarse, solamente, en el cumplimiento del contenido exigido por el sistema educativo, sino que puede también ayudar en la construcción de un lector que reflexione de modo crítico sobre la lengua en la que se expresa y con la que tiene contacto en la literatura de su país. Así la lectura del texto literario apoya sin dudas la construcción identitaria de los pueblos latinoamericanos, pues, de acuerdo a Giardinelli (2007, p. 66), “[...] somos lo que hemos leído. La ausencia o escasez de lectura es un camino seguro hacia la ignorancia y esa es una condena individual gravísima, pero es más cuando deviene colectiva."

La tarea docente, en ese sentido, nos permite la observación de los artistas de la palabra en el continente que históricamente se enfrentan con la dicotomía de reverencia a los modelos instituidos en Europa y la ruptura de los mismos. Este último punto, pasó de ser un plan intelectual para convertirse en la esencia de la propia producción literaria del continente. $\mathrm{Al}$ respecto caben las palabras expresadas por el paraguayo Augusto Roa Bastos, quien en su novela Vigilia del Almirante (1992, p. 333) expone que

[...] el primer paso de una conquista - dice Meliá - es la ocupación de un territorio. Su último paso, el definitivo, se da cuando la lengua de un pueblo ha sido también ocupada. No es extraño pues, que uno de los últimos refugios de la resistencia de los pueblos haya estado siempre en la lengua.

Así, al tratar en la clase de literatura sobre las producciones del continente, advenidas de las lenguas heredadas del Viejo Mundo, nos afrontamos con lo que históricamente ocurrió 
en el propio continente durante su conformación territorial. Es decir, el arte literario forma parte del proceso de construcción identitaria del continente que así como ocurrió con los cambios geopolíticos y conformación de las nuevas naciones, el mismo proceso se dio en aquellos espacios pertenecientes al campo de las ideas, y en definitiva, de la construcción cultural como un todo. En ese sentido, según comenta Salvatore D’Onofrio:

[...] é preciso salientar ainda que o poeta não cria a língua, pois esta é um código comunitário, mas apenas dela se serve de uma forma diferente. Ademais, ele compartilha com a comunidade em que vive não somente o código linguístico, mas também a ideologia, o cabedal cultural, as características bio-psíquicas. A arte é 'uma construção formal baseada em elementos do mundo real' e, como estes, ela possui a qualidade da estruturação. (D’ONOFRIO, 1978, p. 24)

De acuerdo a lo expuesto, la clase de literatura que se plantee un abordaje crítico de los textos literarios nos permite explotar diferentes aspecto de la lengua de comunicación como: 1) estudiar la lengua como constructo social, impregnado de ideología y por lo tanto manipulable; 2) la lengua llevada al campo artístico posibilita diferentes visiones de un mismo discurso y gracias a la identificación del lector con la obra se contribuye con la formación crítica de éste; 3) los mensajes expuestos en la obra literaria pueden ser explotados en confluencia con otras ramas del saber, hecho que manifiesta el potencial de la literatura como expresión cultural de la sociedad e revela lo que defiende Candido (2004, p. 245): “[...] toda obra literária é, antes de mais nada, uma espécie de objeto construído; e é grande o poder humanizador desta construção".

Por lo tanto, el locus enunciativo del docente debe ser claro al momento de llevar a los alumnos las obras literarias que se desean explorar para, de ese modo, elaborar un trabajo consciente y efectivo que contribuya no sólo al conocimiento de determinado grupo de obras establecidas en el canon, sino a la formación de los alumnos como sujetos pensantes y críticos de la sociedad.

\section{El poema de crítica social: una propuesta didáctica para el abordaje del poema en la clase de literatura}

Conforme fue expuesto en la sección anterior, una vez establecido el lugar desde el cual se abordará la obra literaria, y suponiendo que el docente escoja una visión más próxima a las características compartidas por las literaturas latinoamericanas, se pasará al trabajo con la misma. Para ello, elaboramos aquí una serie de cuatro etapas para el trabajo con el poema objeto de este artículo a modo de ejemplo. Las consideraciones didácticas que serán 
efectuadas no intentan ocupar un lugar absoluto ni tampoco buscan ser una salida simple al estudio de la lírica en clase, ya que cada obra demanda un abordaje específico que esté de acuerdo con sus características propias. En este sentido, estamos conscientes que

[...] enseñar literatura es mostrar algo que suscita en el otro una revelación que acaece justamente por el encuentro con lo esencial de la literatura, la diferencia de los textos literarios con los otros discursos sociales. El saber de la literatura solo puede ser saber de la diferencia y la posibilidad de encuentro con uno mismo y con una nueva forma de ver la vida. (NIEVA, 2013, p. 14).

Por lo tanto, el abordaje que será detallado a continuación admite lógicamente modificaciones y, aunque por momentos se realizan generalizaciones, se pretende alcanzar el objetivo de mostrar al docente una posible visión de análisis de la obra artística. Las etapas sugeridas y en las que basamos este estudio son: 1) elección de la autora y su obra; 2) elección de una temática explotada por la autora; 3) lectura del texto literario y análisis del poema y 4) posible trabajo comparado entre literatura y otras artes.

Punto $n^{0} 1$ - la elección de la autora y su obra: en esta etapa del trabajo consideramos que el docente debe establecer cuáles son los fundamentos que encaminaron su tarea de selección de un autor y su obra. Para este artículo fue seleccionada la obra de una poeta paranaense, que a pesar de contar con numerosas críticas y trabajos de investigación de nivel superior, no forma por el momento parte de la historiografía nacional literaria del país luso parlante.

De ese modo, la idea es llevar a la clase de literatura aquellas obras que tienen importancia en determinadas regiones del país para mostrar el pensamiento de una parte de la sociedad letrada y ampliar, de esa manera, el diálogo entre literaturas de diferentes regiones.

Dentro de la explicación sobre la selección tenemos la importancia de la literatura escrita por mujeres en el continente. El canon literario latinoamericano, como fue comentado, se presenta en general como un canon masculino. La cantidad de obras consideradas en las altas esferas de las letras cuenta con pocos nombres de escritoras. Este punto queda aún más evidente cuando buscamos a escritoras que realizaron su producción a partir de la mitad del siglo pasado y de las cuales, por ejemplo, en Brasil, de acuerdo a lo expuesto en los libros especializados sobre literatura, la figura femenina se restringe únicamente a un grupo reducido de mujeres que, por lo general, pertenecieron a los grandes centros económicos del país, descartando otras producciones. 
Estas consideraciones nos permiten reflexionar con el alumnado sobre asuntos clave como la figura de la mujer en el contexto brasileño, la arbitrariedad con la que se juzgaba a aquellas obras escritas por mujeres y su acceso al canon, el desconocimiento de nombres femeninos en las letras del país, entre otros aspectos.

Punto no 2 - elección de una temática explotada por la autora: Esta etapa se refiere específicamente a la temática elegida de todo el conjunto poético que el escritor desarrolla en su obra.

El poema seleccionado se titula "Algemas" y pertenece a la obra Paisagem Interior, escrita originalmente en el año de 1941. Este dato se torna relevante para el debate con el alumnado al momento de establecer diálogos con la historia, por ejemplo. El poema, conforme será observado, teje reflexiones sobre la época en la que fue elaborado: durante la Segunda Guerra.

La selección del poema se estableció para que al mostrarlo como una obra artística se entienda que este objeto es capaz de exponer un mensaje a la sociedad. Esta idea se basa en presentar al alumnado una manera diferente de mirar para la lírica que, por lo general, se identifica con imágenes estereotípicas del género como si su existencia se remitiera únicamente a su escritura en verso, la utilización del recurso de la rima y a veces a un lenguaje poco claro para el lector.

Por medio de una elección cuidadosa del tema podemos llevar a la clase de literatura un producto que, de acuerdo a las exposiciones de Hans Robert Jauss (1989, p. 253), a partir de sus funciones representativas, puede desarrollar la función de comunicación, pues

[...] este hecho poético, que capta la atención del lector por sus interferencias, sus elementos sobredeterminados, y lo somete a una descodificación controlada, tiene que ser portador de una significación, de un 'mensaje'. Si el poema debe imponerse a la atención no sólo por su forma sino también por su contenido, es necesario que el mensaje poético se distinga de la simple información. Podría contener, por ejemplo, una respuesta o solución de especial plausibilidad, dada de manera abierta u oculta, de modo autoritario o ambivalente, pero en todo caso deberá tener un poder de resonancia suficiente para sobrepasar el estímulo ocasional.

El mensaje que pueda transmitir el poema evidentemente puede variar de acuerdo a la temática elegida, sin embargo la transmisión de una idea siempre está presente y es desde allí que el docente debe establecer sus exposiciones. La crítica social es un punto poco explorado aún en la poética de Helena Kolody lo que genera una importancia mayor para llevar al público lector la voz de una mujer cuestionadora de la sociedad y comprometida con la misma. 
Punto no 3 - Lectura del texto literario y análisis del poema: Esta etapa es la más complicada de abordar pues dependiendo del tipo de obra lírica será necesario un análisis diferenciado.

Lo que proponemos aquí es una breve análisis que puede efectivamente ser ampliado y mejorado. No obstante, considerando las múltiples visiones analíticas existentes para el abordaje de la lírica, el docente debe optar por la que mejor se adecúe al poema elegido pero también a su realidad en la sala de clase.

La lectura del poema en el caso de autoras como Helena Kolody debe realizarse en voz alta, debido a que su obra explora la musicalidad de la lengua. Es claro que no siempre podemos conocer esos aspectos de todos los autores que debemos estudiar junto con el alumnado. Sin embargo, siguiendo las consideraciones de la poeta y teórica Idea Vilariño en su obra La masa sonora del poema (2016), el poema es un hecho sonoro y, por lo tanto, su conexión con la voz es vital para este arte.

La lectura del poema puede realizarse en silencio pero después es imperante que en la clase se exponga la obra con la declamación que el poema necesita. La mencionada declamación no debe confundirse con la lectura en voz alta por sí sola, sino que para que ocurra el hecho artístico se debe cuidar de la intención que el poema desea transmitir, por medio de una buena dicción y un tono de voz adecuado. Cuando pensamos en esta especificidad del texto literario, en especial el género lírico, nos acordamos de lo que comenta Montes (2001), cuando se refiere al papel social de la escuela en la formación del lector literario. De acuerdo a la autora:

La escuela puede desempeñar el mejor papel en esta puesta en escena de la actitud de lectura, que incluye, entre otras cosas, un tomarse el tiempo para mirar el mundo, una aceptación de 'lo que no se entiende' y, sobre todo, un ánimo constructor hecho de confianza y arrojo, para buscar indicios y construir sentidos. (MONTES, 2001, p. 7).

Oportunizar al alumnado la audición, y también la práctica, de esta lectura más vuelta para las especificidades de la lírica es, sin dudas, una de esas experiencias constructoras de sentido a las que se refiere Montes (2001), pues es ahí que el sujeto lector puede darse cuenta de la sonoridad que construye un poema, entre otros aspectos peculiares del texto lírico.

A continuación presentamos el poema en el que la escritora construye imágenes mediante una serie de oposiciones con la idea de reforzar la angustia frente a la situación poetizada de la guerra: 


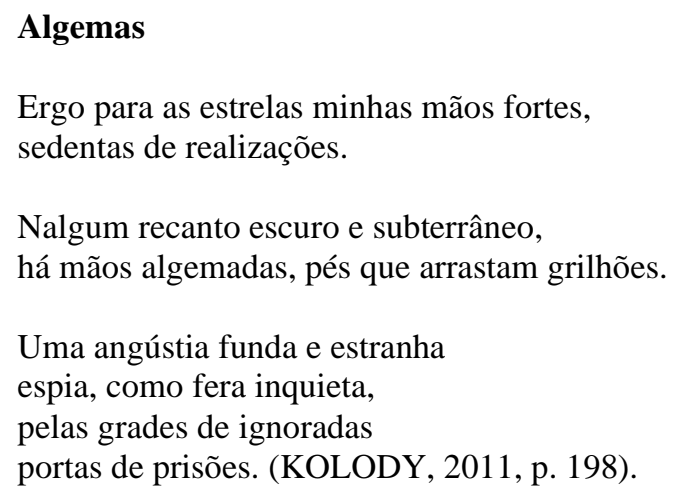

Notamos en este poema, compuesto de ocho versos, divididos en dos pareados y un cuarteto, la presencia de métrica irregular, 11-8, 10-12 y 8-8-7-5. Esta construcción que mezcla diferentes metros está realizada de manera pensada para que el lector encuentre en la disposición de los versos una íntima relación con el discurso que el yo lírico expresa.

De este modo, recordando a lo expuesto por Idea Vilariño (2016) - quien defiende que el verso libre no es tan libre como se cree -, podemos entender la construcción de la estructura planeada para los fines del artista.

En la composición de Helena Kolody se destacan el uso de palabras que evocan imágenes concretas con las que el lector puede diseñar la escena planteada por el yo lírico y, posiblemente, identificarse. El primer pareado es una oración que evoca el momento del acto de levantar las manos, observando el firmamento y la juventud del yo lírico, expresadas con el verbo "ergo" y la adjetivación de las manos: "mãos fortes", "sedentas de realizações". Consideramos que el público, al momento de la lectura de un discurso en primera persona, puede identificarse, pues el poema está trabajando con una acción simple y concreta.

El quiebre del horizonte de expectativas del lector llega en el segundo pareado, en el cual el yo lírico, mediante una reflexión, cambia la imagen del cielo estrellado por la de un "recanto escuro e subterrâneo" y la imagen de las manos fuertes y sedientas de realizaciones es modificada por la de "mãos algemadas" junto con "pés que arrastam grilhões". Por lo tanto, se realiza una transmutación del carácter romántico, expuesto en la primera parte, para, en la segunda, reflexionar sobre la compasión, o colocarse en el lugar del otro y, así, revelar la sensibilidad de la poeta por la expresión de la alteridad.

La tercera parte del poema trae la voz del yo lírico que remete a la imagen de un prisionero olvidado. Nótese que la escritora para esta sección del poema utilizó un cuarteto 
construido por encabalgamiento, hecho que realza la sensación de angustia que el yo lírico desea transmitir sobre la escena en cuestión.

Se puede decir que existe un desplazamiento de la escena propuesta desde el comienzo en tres partes diferentes: la primera es la visión de las propias manos erguidas al cielo, la segunda, es la transformación de esas manos y del espacio por una que evoca el cautiverio y, la tercera, es la imagen de la mirada angustiada detrás de las rejas de las prisiones.

La importancia de este tipo de poemas en la poética de Helena Kolody se fundamenta en que, como ya fue comentado, el conjunto de su obra todavía no fue estudiado desde esa perspectiva más crítica, quizá, por la preservación de su imagen como mujer-escritora, insertada en conformidad con la sociedad que cultiva esa faceta más romántica de la mujerprofesora. La composición fue creada justamente en la época de la Segunda Guerra Mundial, hecho que causaba perturbación a nivel global, preocupación que esta mujer-poeta plasmó en su escritura.

Punto no 4 - Posible trabajo comparado entre literatura y otras artes: en la cuarta etapa propuesta pensamos en la necesidad de establecer diálogos con otras artes, mostrando la amplitud que el objeto artístico literario tiene para relacionarse con otro tipo de expresiones.

El docente puede optar por realizar una tarea comparativa con el arte al cual tenga mayor afinidad y dominio. No obstante, este punto presenta una seria cuestión que debe ser analizada. La comparación del poema con otras ramas del arte como la música, la pintura, la danza, etc. no puede quedar en la visión simplista de colocar al lado de la palabra un cuadro que tenga más o menos el mismo tema y pensar que el diálogo interartístico está realizado. $\mathrm{O}$, por ejemplo, exponer un poema crítico y pasar a la audición de una música de protesta sin realizar la mínima consideración técnica sobre los aspectos estructurales que el arte del sonido amerita.

Por lo tanto, para evitar confusiones que lleguen a degenerar la importancia del comparatismo entre artes debemos cuidar desde que ángulo analizar, pedir ayuda si la necesitamos con especialistas para no banalizar la labor comparativa en la clase de literatura.

Para esta etapa decidimos comparar el poema con las artes visuales, específicamente el dibujo. Nuestra elección de este arte se debe a la cierta facilidad con la que el docente puede encontrar obras que dialoguen en temática y poética así como los períodos históricos y los recursos físicos accesibles que tenemos comúnmente en el aula. 
La propuesta en este caso se basa en la elaboración de una obra siguiendo la secuencia de imágenes que el poema presenta.

Para la elaboración de la obra pictórica basada en el poema se optó por un trabajo sencillo de carbón sobre papel con la idea de que son materiales de fácil acceso y posible de utilizar en el aula. Así como el poema en el primer pareado muestra una visión que remete a un espacio abierto como símbolo de libertad, la obra realizada buscó exponer este sentimiento siguiendo la imagen de las "mãos erguidas ao céu".

Consideramos que así como el lector del poema al momento de la declamación puede identificarse con este acto y así conseguir una aceptación del discurso del poema como propio, el dibujo puede hacerlo de ese modo también.

Para ello la primera imagen expresada en el papel se colocó en la parte superior con un fondo que representa un cielo estrellado.

El poema presenta un juego de contrastes que en el segundo pareado exponen las manos esposadas. Es decir, que la visión de las manos elevadas al cielo baja y el lector podría vislumbrar las mismas o propias manos en una situación diferente. El dibujo intenta expresar este recorrido de la mirada desde la parte superior hasta la inferior en el cual las manos cambian de posición y pasan a estar esposadas.

La tercera y última estrofa del poema reflexiona sobre el sentir del sujeto que mueve la reflexión del yo lírico. Para expresar esta cuestión se opta por un dibujo en perspectiva de un ser sin definición de género, puesto que el poema no lo especifica, que sufre el cautiverio.

Los tonos utilizados en este caso se dan por el uso del carboncillo, jugando con las ideas de luz y sombra. Es importante notar que así como el poema expresa una angustia frente a los que padecen la falta de libertad, así también la obra en la elección de la tonalidad intentó adaptarse al contenido de la obra lírica. Como ejemplo de ello sigue el dibujo basado en el poema de la autora paranaense:

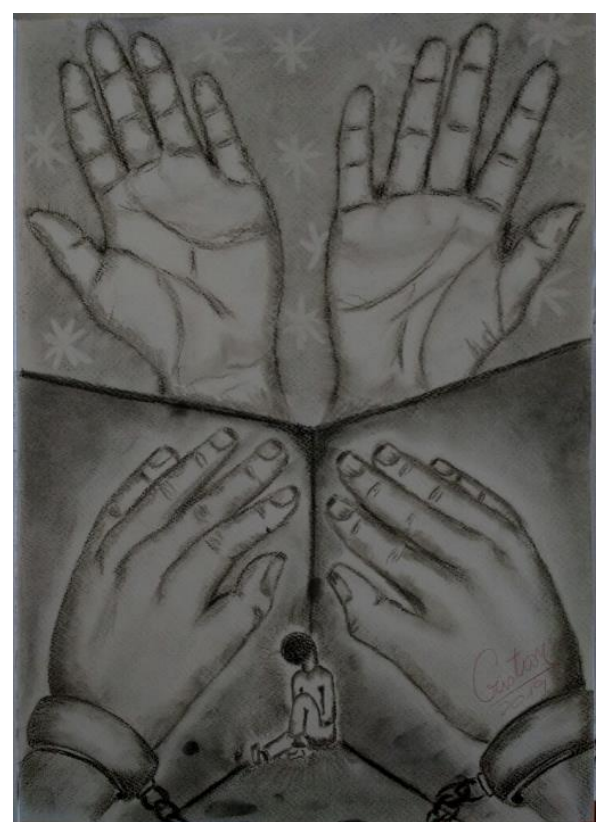


Obra: "Algemas", dibujo de Cristian Javier López (autor).

Técnica: Carboncillo sobre papel A3.

Las opciones de técnicas de artes visuales para utilizar en el aula son diversas y no necesariamente se debe seguir una u otra. Este tipo de trabajo creativo podría realizarse de manera inversa al presentar una obra pictórica y pedir a los alumnos la escritura de una composición lírica basada en ella a modo de taller literario.

Consideramos que la exploración de las capacidades integrales son una de las claves para el proceso de enseñanza y aprendizaje y por lo tanto demostrar una creación derivada de un poema desde nuestra perspectiva puede tornarse provechosa independientemente del grado de dominio técnico artístico. Aquí también pensamos en lo que defiende Rouxel (2013, p. 162) para el uso del texto literario en clase: “[é] indispensável hoje fomentar entre os alunos uma abordagem sensível dos textos, [...] o desafio é fazer viver uma experiência de leitura, sem a qual a atividade, puramente cerebral, não faria sentido algum aos alunos."

Además, de este tipo de trabajo comparativo nacen las diferentes visiones elaboradas en las obras realizadas por los propios alumnos que dialogarán con la lírica estableciendo contactos que estimulen la imaginación y la lectura crítica de las obras en general.

\section{Considerações finais}

La obra lírica nos permite su estudio desde diferentes perspectivas tanto cuando analizamos su estructura, su mensaje o su contexto de producción. Es decir, que como docentes podemos usar, cuando sea posible, diferentes propuestas para llevar a nuestros alumnos el estudio de un poema, sin limitarnos a una exposición simple basada en el texto distribuido en versos.

De las diferentes perspectivas que podamos usar, como profesores debemos conocer cuál es el lugar de enunciación de los poetas con quienes trabajaremos en la clase. Este punto nos ayuda a entender la obra, su autor, el contexto de producción y los elementos que indefectiblemente se relacionan con el objeto artístico. Con ello, el estudio del poema no sólo nos demuestra su amplio espectro de actuación sino que nos abre el camino al conocimiento de la relación autor, obra y público, comprendiendo de manera global la producción lírica analizada.

Los análisis de los poemas elegidos pueden realizarse de diversos modos que varían de acuerdo a la obra, al estilo, a la época etc. y dependerá de la visión del profesor para que se 
explote al máximo el potencial de la obra. Lógicamente hay una base fija que el arte lírico cumple por cuestiones propias del género como la métrica, el ritmo, entre otros, sin embargo el poema como hecho artístico no se basa tan sólo en uno de estos aspectos y si en su constitución global en la que confluye forma, sonido y mensaje.

Las relaciones que el poema nos permite con otras ramas del saber, sean artísticas o científicas, también dependerá de la obra aunque en todo caso siempre es posible encontrar conexiones con otros saberes, puesto que estamos hablando de un objeto artístico oriundo de una cultura específica con significación social.

Este punto nos ayuda en la clase de literatura a exponer los diálogos interartísticos, por ejemplo, hecho que nos abre el horizonte a nuevas posibles lecturas de la obra. Tales lecturas incentivan a una exploración de las capacidades críticas del alumnado y fortalecen el proceso de enseñanza y aprendizaje ya no sólo en el ámbito literario sino también en un sentido global. Por lo tanto, consideramos que los trabajos que propongan la exploración consciente del arte de la palabra junto con otros saberes conseguirán colaborar de manera concreta con la educación de los sujetos, ampliando no sólo sus saberes sino la visión crítica de la propia lengua.

\section{Referencias}

CANDIDO, Antonio. Inquietudes na poesia de Drummond. In: Vários escritos. 4. ed. (reorganizada pelo autor), São Paulo: Duas Cidades; Rio de Janeiro: Ouro sobre Azul, 2004.

D’ONOFRIO, Salvatore. Poemas e Narrativas: estruturas. São Paulo: Duas cidades, 1978.

JAUSS, Hans Robert. La douceur du foyer-La lírica en 1857 como ejemplo de transmisión de normas sociales. In: WARNING, Rainer. (Ed.). Estética de la recepción. Madrid: Visor, 1989.

KOLODY, Helena. Infinita Sinfonia. A. M. WOELLNER (Org.) Curitiba, PR: Edição do autor, 2011.

MONTES, Graciela. La frontera indómita: en torno de la construcción y defensa del espacio poético. Buenos Aires: F.C.E., 2001.

NIEVA, Elba Rosa Amado. Volver a leer - El papel del docente en la recuperación del poder y el placer de la lectura. Revista do Departamento de Investigação da Escola Normal Superior Juan B. Alberdi. Disponível em: http://www.imaginaria.com.ar/17/9/lo-que-puedela-literatura.htm. Acesso em: 21 nov. 2013.

PAZ, Octavio. Convergencias. Barcelona: Seix Barral, 1991. 
ROA BASTOS, Augusto. Vigilia del Almirante. Madrid: Alfaguara, 1992.

ROUXEL, Annie; LANGLADE, Gérard; REZENDE, Neide Luzia de. (Orgs.). Leitura subjetiva e ensino de literatura. São Paulo: Alameda, 2013.

SILVEIRA, Maria Inez Matoso. Modelos Teóricos e Estratégias de Leitura: suas implicações no ensino. Maceió: EDUFAL, 2005.

SOARES, Magda. Alfabetização e Letramento, Caminhos e Descaminhos. Revista Pátio. ano VIII, n. 29, p. 20, fev/abr. 2004.

VILARIÑO, Idea. La masa sonora del poema. Montevideo: Biblioteca Nacional, 2016.

Recebido em 30 de agosto de 2019. Aceito em 05 de novembro de 2019. 